\title{
O QUE PODEMOS APRENDER COM AS CRIANÇAS INDÍGENAS? APROXIMAÇÕES DA ANTROPOLOGIA DA CRIANÇA ÀS NOÇÕES DE INFÂNCIA, CULTURA E MOVIMENTO NA EDUCAÇÃO FÍSICA
}

\author{
MS. IRACEMA MUNARIM \\ Mestre em Educação pelo Programa de Pós-graduação em Educação da \\ Universidade Federal de Santa Catarina (PPGE/UFSC) \\ Drnda. em Educação pelo PPGE/UFSC (Florianópolis - Santa Catarina - Brasil) \\ e-mail: ira_munarim@yahoo.com.br
}

\begin{abstract}
RESUMO
Este artigo se propõe a questionar as noções de infância, cultura e movimento presentes na Educação Física a partir das contribuições da Antropologia da Criança, a qual demonstra, em especial, nos estudos em sociedades indígenas o quanto identidade e subjetividades infantis constroem-se por meio de processos que se realizam através da corporalidade. Nesta reflexão são abordados os conceitos de infância na sociedade ocidental, partindo do princípio de que a infância não deve ser considerada como categoria natural ou universal, determinada por aspectos biológicos, e que suas determinações são variáveis, histórica, cultural e socialmente.
\end{abstract}

PALAVRAS-CHAVE: Infância; corpo; movimento; antropologia da criança. 


\section{INTRODUÇÃO}

A intenção deste artigo é contribuir para o debate sobre as diferentes concepções de infância, cujos significados e formas como são vividas dependem de fatores que transitam nos mais diversos contextos sociais e culturais. Destaco a importância desta discussão na área da Educação Física que, historicamente, tem apresentado reflexões a partir da ideia de infância como uma categoria única, biológica e homogênea ${ }^{1}$. Discutir o que é ser criança na Educação Física vai muito além de propor jogos e brincadeiras e definir atividades motoras para cada faixa etária. Pensar a infância e a noção do lugar que as crianças ocupam em nossa sociedade reflete tanto a forma como articulamos propostas em nível de políticas públicas - planejamentos urbanos, projetos de lazer e infraestrutura das cidades, que ainda privilegiam o adulto e suas atividades - como nas definições de conteúdos a serem trabalhados na escola, nos espaços e tempos a elas destinados. Não basta compreender a importância do brincar, do imaginário que envolve o cotidiano das crianças, mas também propor - e respeitar - as condições e os meios para que as brincadeiras aconteçam.

Assim, no intuito de contribuir para esta reflexão, tomo como embasamento teórico referenciais de estudo sobre infância, em especial no contexto indígena, tendo como foco as abordagens da Antropologia da Criança². Como afirmado anteriormente, parto do princípio já reforçado por outros autores (BUCKINGHAM, 2007; SARMENTO, 2004; GIRARDELLO, 1998) de que a infância não é uma categoria natural ou universal, determinada por aspectos biológicos, mas que suas determinações são variáveis, histórica, cultural e socialmente. Partindo deste ponto de vista, entendo que uma das grandes contribuições da Antropologia da Criança para a Educação Física seja a provocação de que não podemos continuar olhando para o ser humano apenas com os óculos biológicos (DAOLIO, 2005). A inserção da cultura nos estudos da Educação Física demonstra que é cada vez mais necessária a compreensão de que existem diferenças socioculturais entre os seres humanos e que o entendimento de corpo deve ir além da sua concepção mecânica, biológica, da tão falada dualidade corpo e mente.

A Antropologia da Criança, ao abordar a realidade das crianças indígenas, demonstra a importância de voltar nosso olhar para as infâncias distantes dos bancos

I. Para saber mais: Daolio (1995); Paiva (1992).

2. A intenção inicial deste texto não era tratar especificamente de crianças indígenas, mas falar das diferentes infâncias tendo como base estudos da Antropologia da Criança, que na sua maioria abordam o mundo vivido das crianças indígenas. 
escolares, que passam por privações, mas também por experiências significativamente ricas corporalmente. Para crianças cuja cultura e entendimento sobre a constituição de pessoa são centrados no corpo, cosmológico, nos seus rituais de ornamentos e pinturas, de ritmos e danças, dos cuidados e crenças durante a gestação, do rapto e do infanticídio. Para modos de vida que nos mostram que identidade e subjetividades infantis constroem-se por meio de processos que se realizam em seus corpos, compreendendo a corporalidade como um dos mecanismos centrais na aprendizagem e transmissão de conhecimentos, habilidades, técnicas e concepções próprias à educação das crianças (SILVA, 2002, p. 40). Em suma, é a demonstração de uma das faces das diversas infâncias dentro da "infância global".

\section{PARA COMEÇAR: CONSIDERAÇÕES HISTÓRICAS E OCIDENTAIS SOBRE INFÂNCIA ${ }^{3}$}

Pesquisar um tema de estreita ligação com as crianças nos remete inevitavelmente à tarefa de definir ou pelo menos situar o leitor no ponto de vista sobre a infância do qual partimos. Ainda que a infância seja um período comum a todos os seres humanos, afinal todo adulto um dia já foi criança, responder à pergunta "o que é ser criança?" muitas vezes acaba em uma rede de definições contraditórias ou em relatos de experiências vividas por quem responde à pergunta. São essas memórias que, segundo Cohn (2005), muitas vezes nos levam a entender que tudo já foi respondido e que não existem mais dúvidas sobre o que é ser criança.

Nos últimos anos, principalmente com a rápida evolução das tecnologias de comunicação e seu acesso facilitado às crianças, os debates sobre o tema assumiram um caráter cada vez mais contraditório. Prova disso são as definições diferentes, confusas ou alarmantes, encontradas na literatura, nas mídias ou no senso comum: a criança vista como tábula rasa (como um ser vazio e desprovido de conhecimentos, à espera da educação dos adultos); a infância vista como um paraíso perdido (para onde nunca mais os adultos podem voltar); as crianças vistas como anjos de inocência e pureza ou como "demoniozinhos a serem domesticados". Muitas vezes a infância também é pensada como algo muito distante, inacessível, exceto pela memória e pelas recordações, por meio das quais alimentamos a ideia dessa fase da vida como uma época misteriosa, mágica, pura. Mas, ao nos afastarmos de nosso mundo imaginário, parecemos não saber mais o que é ser criança pois nossas

3. Parte das reflexões deste artigo é recorte de minha dissertação de mestrado defendida em 2007 no Programa de Pós-Graduação em Educação da Universidade Federal de Santa Catarina (MUNARIM, 2007). 
lembranças de um tempo passado já não se parecem mais com as experiências das crianças de hoje. Se pensarmos na ideia de que cada um define o que é ser criança de acordo com sua própria vivência, o contraste com o modo de vida das crianças de hoje é cada vez maior. Se as características das infâncias ${ }^{4}$ contemporâneas são marcadas de modo especial pelo acesso às tecnologias, buscar na história o que é ser criança mostra-se ainda mais delicado.

Historicamente, a criança tem sido definida por sua faixa etária e considerada como um ser ainda em formação. Durante a Idade Média, encaradas como pecado original, pequenos monstros ou adultos incompletos e irracionais - que necessitavam de uma educação rígida para correção e disciplinamento - as crianças eram consideradas meros seres biológicos, sem estatuto social nem autonomia existencial (SARMENTO, 2004). Nem mesmo as vestimentas faziam diferenciações entre os adultos e crianças. Como demonstra Ariès ( $198 \mid$ ), na Idade Média assim que as crianças deixavam os cueiros (faixas nas quais eram enroladas), eram vestidas conforme os adultos, de acordo com sua classe social. Além dos trajes idênticos, as crianças participavam dos mesmos rituais diários dos adultos, inclusive nas brincadeiras.

Apenas no século XVII as crianças começaram a ser vistas de forma diferenciada e, embora muito timidamente, como uma categoria geracional à parte - momento em que surgiram os primeiros traços da visão romântica da criança, como um ser natural, puro e inocente. Mas foi com a expansão da indústria capitalista que as definições de infância se consolidaram, criando-se o entendimento tipicamente moderno do que é ser criança. É o que nos mostra Walter Benjamin, ao relacionar a economia com os conceitos de infância, principalmente através da burguesia do século XVIII. Segundo ele, o fosso entre o adulto e a criança ficou ainda mais claro com a emancipação dos brinquedos, processo em que estes se tornaram objetos voltados às crianças (antes disso, os brinquedos eram utilizados como enfeites, miniaturas ao gosto dos adultos). Como consequência disso, surgiu a profissão do vendedor de brinquedos, exatamente num período da mais rigorosa especialização comercial, que tornou o brinquedo, antes produto secundário das manufatureiras, uma mercadoria economicamente interessante de ser comercializada (BENJAMIN, 1984).

Além do comércio de brinquedos, a educação foi outro fator importante na definição da categoria infância. De acordo com Kline (1993) no século XIX surge a ideia da criança inocente, com necessidade de aprendizado e formação, devendo

4. A utilização do plural está de acordo com a ideia de que a infância não deve ser resumida a uma categoria fixa, imutável e homogênea. A vivência, o contexto cultural, a experiência de cada criança faz com que existam diversas infâncias, muitas diferentes entre si (SARMENTO, 2004; BUCKINGHAM, 2000). 
ser protegida da áspera realidade da sociedade industrial. Aos poucos, as crianças começaram a ser excluídas mais e mais das arenas cruciais da vida e dos conflitos que marcavam o desenvolvimento da época. Em compensação, a elas foram garantidos direitos de proteção e um espaço institucional separado: as escolas, que estabeleceram a nova agenda para seu aprendizado.

Partilham desta mesma ideia autores como Sarmento (2004), segundo o qual a institucionalização da infância no início da modernidade aconteceu devido à junção de vários fatores, sendo o primeiro deles, senão o principal, a expansão da escola pública e a obrigatoriedade da educação, e Buckingham (2007), ao lembrar que o confinamento das crianças em salas de aula fazia parte do projeto iluminista, que dava ênfase ao desenvolvimento da racionalidade enquanto um meio de assegurar a estabilidade da ordem social. Para Buckingham, a caracterização das crianças como irracionais justificava o longo período no qual elas pudessem ser treinadas nas artes do autocontrole e do treinamento. Concomitantemente a isto, a família, que antes, se tinha posses, delegava o cuidado das crianças às criadas, começou a centralizar as responsabilidades de proteção e estímulos ao desenvolvimento das crianças. Destaca-se neste mesmo momento a constituição de saberes sobre a infância, do entendimento da criança como um "vir a ser", com a criação de áreas específicas da medicina, psicologia e pedagogia, como a pediatria e a psicologia do desenvolvimento (SARMENTO, 2004). Como afirma Walkerdine (1995), "as concepções científicas 'da criança' tornaram-se não simples descrições, mas parte de estratégias planejadas para 'conhecer' a criança de uma forma melhor, a fim de regulá-la" (WALKERDINE, 1995, p. 2 I0).

Na mesma discussão sobre a criança vista como um ser ainda em formação, Perrotti (1990) assinala como a caracterização evolucionista da criança atribui o critério valorativo aos adultos como "seres completos" que são. Para chegar a tal estágio, a criança é definida como um 'vir a ser', devendo ser lapidada, educada para determinado fim. Ao situar as visões adultocêntricas sobre a criança, Perrotti destaca a ideologia dominante (não se referindo apenas aos discursos de conservadores, mas também os discursos liberais de democratas) para a intensificação da visão da criança como elemento culturalmente passivo. E é esta visão, de negação da criança enquanto produtora de cultura, que define e classifica os sujeitos de acordo com o grau de envolvimento que cada um mantém com a produção. "Daí a sociedade capitalista privilegiar o adulto, pois ele pode ser mais 'produtivo' que a criança, dentro do modo como está organizada a produção" (PERROTI, I990, p. 18). Sob este esquema de exclusão, segundo Perrotti, encontram-se descartados enquanto produtores de cultura não apenas as crianças, como também os idosos, cuja força produtiva diminui com o passar do tempo nos termos capitalistas, assim 
como pessoas que, de uma forma ou de outra, não se ajustam às leis de convivência vigentes pelo sistema produtivo, como deficientes físicos, artistas, "loucos", etc. Mesmo com a naturalização das distinções na vida em sociedade, o autor destaca que a oposição ativo/passivo é histórica e não natural, sendo as construções das relações de produção próprias do ser humano.

Do mesmo ponto de vista, e situando a categorização da infância, Buckingham (2007) demonstra como as crianças são definidas como uma categoria particular com características próprias e universais, tanto por si mesmas como pelos outros (pais, instituições, meios de comunicação). Estas definições se materializam em forma de práticas sociais e institucionais, caracterizando e produzindo as formas de comportamento tipicamente "infantis". Como exemplo, o autor cita a escola e a família como instituições sociais que constroem características da infância, bem como definem seu lugar ocupado na sociedade, reforçando pressupostos sobre como as crianças são e deveriam ser. Assim, Buckingham aponta para a necessidade de se questionar a noção de que tenha sido na idade moderna que as crianças tiveram suas 'necessidades' reconhecidas, pois tais definições de necessidades, assim como de características da infância, são construídas cultural e historicamente, "implicando formas particulares de organização social e política" (BUCKINGHAM, 2007, p.9).

Compreende-se assim que a ideia de infância pode variar em culturas ou sociedades diferentes, ou até mesmo inexistir, como se constata, por exemplo, no estudo de Cohn (2005) sobre crianças indígenas no Brasil. Mas, embora a infância seja alvo de diversas concepções, parece que há uma insistência de nossa sociedade em caminhar para uma esfera homogeneizadora, que trata a infância como global, possuidora de características próprias e iguais em qualquer lugar do mundo. Partindo deste entendimento, trago de minhas experiências tanto como professora quanto como pesquisadora o intuito de compreender cada vez mais o mundo vivido das crianças, principalmente no que diz respeito aos diferentes tempos e lugares da infância, da cultura, do corpo e do movimento.

Nesta conjuntura, as contribuições da Antropologia da Criança reforçam a importância de se buscar outras fontes de conhecimento que fogem daquelas consideradas tradicionalmente como legítimas, que escapam das rotinas entre muros da escola, dos clubes e condomínios fechados. Aquela infância cujos significados, assim como a forma como ela é vivida, dependem de diversos fatores sociais e culturais. Diferentes culturas nas quais o tempo, o respeito às opiniões e a liberdade de ir e vir das crianças contrasta com o modo de vida de grande parte das crianças matriculadas nas escolas das cidades, bem como do lugar que nós adultos destinamos a elas em nossa sociedade. 


\section{APROXIMAÇÕES À ANTROPOLOGIA DA CRIANÇA}

A abordagem da Antropologia aos estudos com crianças é relativamente recente, considerando, como afirma Tassinari (2007), que só na última década que se partiu para uma abordagem atenta a elas como sujeitos sociais e não apenas como objetos passivos da educação.

Mesmo ainda sendo uma área recente nas Ciências Sociais, Nunes (2002) traz um quadro de referências representativo da literatura etnológica entre as décadas de 1970 e 1990, que abordam questões cruciais em favor da possibilidade de uma Antropologia da Criança. Segundo ela, até a década de 1990, as pesquisas em etnologia indígena, em geral, se delimitavam na descrição sobre como se organizava determinado grupo doméstico, sobre as várias fases do ciclo de vida de cada indivíduo. "As referências às crianças, quando não dispersas por todo o texto em simples alusões figurativas, ocupam de uma a cinco páginas, salvo raras exceções" (NUNES, 2002, p. 239). Assim, o ponto de partida, objeto de intervenção das pesquisas, não eram crianças que pertenciam a determinado grupo doméstico, mas grupos domésticos aos quais pertenciam algumas crianças. E grande parte dos registros, principalmente os pioneiros nas observações em terras baixas sulamericanas, tinham como foco o comentário sobre questões tão adversas como a grande participação dos pequenos nas decisões da tribo (a agência das crianças) e a liberdade de ir e vir dentro da aldeia em contraponto com o infanticídio e o rapto de crianças, crueldades e barbáries a olhos de estranhos. Neste sentido, os esclarecimentos sobre atos tão adversos como esses tornam-se desafios àqueles que têm como foco de suas pesquisas as crianças indígenas. Afinal, como questiona Tassinari (2007, p. 13), "como explicar atitudes aparentemente tão antagônicas em relação às crianças, da paciência extrema com as atitudes delas à crueldade do assassinato ou do rapto?".

Tal qual Nunes (2002), que propõe que se dê mais espaço às crianças nos estudos antropológicos/etnológicos, já que são abordagens ainda incipientes, Tassinari (2007) reforça que para se aproximar dos conceitos nativos de infância é necessário o afastamento das imagens dicotômicas de candura ou crueldade que dizem respeito às nossas concepções de infância, bem como tentar entender a forma como os indígenas a compreendem.

As crianças indígenas têm liberdades de escolha que parecem impossíveis para nós, de cultura ocidental, já que quando as analisamos sempre olhamos pelo ponto de vista da tutela, nos espantando o respeito de uma tribo à escolha das crianças. A criança indígena ocupa um lugar mais relevante do que a nossa criança (ocidental), é tratada como um outro ser, cosmológico, em sua relação com a sociedade e com 
a natureza. Um outro que pode ter mais conhecimentos que os adultos, que possui sua especificidade, seu lugar reconhecido dentro de sua cultura. Neste sentido, como demonstra Tassinari (2007, p. 23),

[...] Ao contrário de nossa prática social que exclui as crianças das esferas decisórias, as crianças indígenas são elementos-chave na socialização e na interação de grupos sociais e os adultos reconhecem nelas potencialidades que as permitem ocupar espaços de sujeitos plenos e produtores de sociabilidade.

Foi a partir deste ponto de vista, aqui demonstrado por Tassinari, que surgiu o divisor de águas nos estudos sobre crianças dentro da Antropologia, quando, enfim, é reconhecida na área a capacidade de agência das crianças. De que "a criança não só participa, mas que a sua participação pode adicionar algo à vida social, transformando-a" (NUNES; CARVALHO, 2007, p. 4). Muito embora, como afirmam as autoras, seja ainda difícil identificar o que é esse algo que as crianças adicionam e o impacto de sua ação na vida em sociedade.

Neste sentido, a Antropologia da Criança se baseia numa crítica principalmente aos estudos de socialização, no qual a criança teria que se adaptar à cultura da qual faz parte. Surge como um novo paradigma, mostrando as várias possibilidades da infância, que não é única, com mais autonomia e participação. E é no surgimento deste paradigma que Nunes e Silva (2002, p. 18) apresentam, a partir da idealização de James e Prout ( 1990 apud NUNES; SILVA, 2002), os seis princípios que poderiam estar na base destas reflexões:

I) Entender a infância como construção social;

2) A infância deve ser considerada como variável para análise social (como gênero, classe ou etnia);

3) Relações sociais e cultura infantil devem ser estudadas em si mesmas;

4) Crianças devem ser vistas como ativas na construção e determinação da sua vida social;

5) A etnografia é particularmente útil nas pesquisas como método que dá voz às crianças ${ }^{5}$;

5. A expressão "dar voz às crianças" corresponde a uma referência retirada de obra de outros autores. Contudo, é necessário problematizar essa afirmação: devemos dar voz ou ouvidos às nossas crianças? Mesmo aquelas crianças que ainda não estão oralizadas se expressam de diversas outras maneiras. Em suma, as crianças foram pouco ou quase nada ouvidas, mas elas sempre tiveram voz. 
6) A infância é um fenômeno no qual uma dupla hermenêutica nas Ciências Sociais está presente: pensamos a infância na Antropologia e também a nossa sociedade (a Antropologia passa a entender certos fenômenos quando se volta para a criança).

Um ponto de partida importante mostrado por estes seis princípios resumese na mudança do olhar de quem se volta para a criança, na sugestão de olhar para a criança sem apenas a perspectiva do ensinar. Escutá-las mais, observá-las mais, entender como se dá o processo de socialização destas, inclusive nas escolas, sem a intenção de pedagogizar todos os seus movimentos, as suas brincadeiras, os momentos que fazem parte do diálogo que estabelecem com o mundo.

Assim, embora a reflexão que aqui se apresenta não tenha a profundidade que me caberia propor, relato neste espaço algumas inquietações que surgem cada vez que volto meu olhar às escolas tradicionais, digo, não indígenas. Principalmente quando me deparo com a forma como a Educação Física tem se constituído neste campo de práticas e saberes que é a instituição escolar. Caberia, pois, perguntar como a Antropologia da Criança pode contribuir nesta discussão da relação construída entre a Educação Física e a cultura [corporal] de movimento que é perpassada pelo entendimento do que é ser criança6.

De acordo com SILVA (2002), no contexto ameríndio, a identidade e subjetividades infantis constroem-se por meio de processos que se realizam em seus corpos e a mesma direção está se delineando nas perspectivas de pesquisas sobre criança. Neste sentido, o que temos a aprender com esta abordagem das crianças indígenas em relação ao corpo? Se nas sociedades indígenas a pessoa é constituída culturalmente através do seu corpo e seus adornos (SEEGER; DAMATTA; VIVEIROS DE CASTRO, 1979), sendo toda a educação voltada a aspectos corpóreos, como podemos pensar essa constituição de pessoa a partir da corporeidade em nossa cultura ocidental, na qual a Educação Física na escola é periférica, os corpos são domesticados, as expressões e os sentidos são contidos, tudo em detrimento do possível desenvolvimento da mente?

que os estudos sobre as sociedades indígenas demonstram, ainda mais evidente do que nossos estilos de vida ocidentais - e para isso vale ler as pesquisas que relatam as diferentes formas de viver nas sociedades indígenas ${ }^{7}$ - que a pessoa

6. Sobre concepções de infância na Educação Física brasileira, ver: Cruz de Oliveira (2003).

7. Para saber mais, consultar anais do Encontro Anual da Anpocs (Associação Nacional de Pós Graduação e Pesquisa em Ciências Sociais) e da Reunião de Antropologia do Mercosul (RAM), dois grandes eventos que reúnem pesquisadores da área. 
é social a partir do que seu corpo é produzido socialmente. Como afirmam Seeger, DaMatta e Viveiros de Castro (1979, p. 4),

a produção física de indivíduos se insere em um contexto voltado para a produção social de pessoas (...) Perguntar-se, assim, sobre o lugar do corpo é iniciar uma indagação sobre as formas de construção da pessoa.

Em outro momento, os mesmos autores elucidam como a noção de pessoa no Ocidente parte da "noção de indivíduo onde a vertente interna é exaltada" e nas sociedades tribais, o lado coletivo se configura "como instrumento de uma relação complementar com a realidade social". Assim, para entendermos o sentido de "pessoa" temos que apreender também todo esse cuidado que envolve a produção da pessoa - no caso dos indígenas, as superstições, crendices na gravidez e nascimentos, as cerimônias para escolha do nome da criança, a comunicação por sonhos, os mitos e lendas, as diversas formas de aprendizagem. Como se vê, tudo baseado no que passa pelo corpo, no que entra ou sai dele. Desta forma, sugerem os autores, as noções ligadas à corporalidade e construção da pessoa são inerentes.

Assim, pesquisadores demonstram em seus relatos sobre as sociedades indígenas que quase toda a educação é uma educação pelos corpos, do que se pode ou não fazer. Nesse sentido, pode-se citar o relato de Cohn (2000) sobre as crianças Kayapó-Xikrin que, assim como outras tribos, valorizam os sentidos na comunicação e aprendizagem. Entre elas, segundo a autora, o corpo da criança precisa desenvolver uma integração entre seus elementos internos: desenvolver os órgãos da compreensão durante a infância, como é caso do coração, para armazenar os conhecimentos e deixar seu corpo "duro" para que a alma não saia de seu interior. Mead (195I) nos traz outro exemplo ao escrever sobre as crianças balinesas que passam boa parte de suas infâncias no colo de adultos. Já nas crianças Marubo, apresentadas por Melatti e Melatti (1979), são aplicadas urtigas em seus braços ou costas para tirar-lhes a preguiça para o trabalho ${ }^{8}$. $\bigcirc$ que estes autores trazem em comum, como bem demonstram Seeger, DaMatta e Viveiros de Castro ( 1979 ) é que "o corpo é uma matriz de símbolos e um objeto de pensamento". E nas sociedades indígenas do Brasil, esta matriz ocupa posição organizadora central onde a fabricação, decoração, transformação e destruição dos corpos são temas em torno dos quais giram as mitologias, a vida cerimonial e a organização social (SEEGER; DAMATTA; VIVEIROS DE CASTRO, 1979, p. I I).

8. A relação infância e trabalho também merece uma discussão a parte, principalmente no que diz respeito ao entendimento destes conceitos em diferentes culturas. 


\section{REFLEXÕES PARA A EDUCAÇÃO FÍSICA}

Como vimos, no contexto indígena o corpo é central para pensar a sociedade e o cosmos, embora existam diferenças do lugar da corporalidade entre si (ecológicas, de organização social, cosmológicas). E, "o corpo físico, por outro lado, não é a totalidade de corpo; nem o corpo a totalidade da pessoa" (SEEGER; DAMATTA; VIVEIROS DE CASTRO, 1979, p. 13). E é este outro lado, da relação das sociedades indígenas com o corpo que nos mostra, em uma situação de contrastes, a relação que estabelecemos com nossas crianças. Enquanto estamos exigindo a motricidade fina de crianças, sentadas, cabeças baixas de olho no caderno e lápis na mão, crianças indígenas de três anos já trabalham com habilidade usando um facão. Enquanto fechamos os portões com cadeados e delimitamos os espaços de movimento com grades e concretos, além dos tempos ocupados com atividades extraclasse, crianças indígenas nos ensinam o quanto a liberdade para experimentar sensações junto à natureza ampliam nosso repertório de conhecimentos sobre o mundo em que vivemos. Nos ensinam que as sensações e movimentos são instrumentos importantes do aprendizado e da expressão dos conhecimentos em elaboração (SILVA, 2002, p. 42).

Destas afirmações surge o questionamento de como as crianças são tratadas em nossa sociedade e do porquê tanto nos espanta este tempo diferente em que vivem as crianças indígenas, não lapidado pelo tempo khronos das sociedades de consumo. Do quanto nos parece estranha essa liberdade das crianças em transitar nas mais diversas esferas sociais, com autonomia no seu aprendizado (dentro ou fora de escolas indígenas, o que renderia outra discussão), marcado por experiências de vida ligadas ao corpo e aos sentidos.

Será mesmo que continuamos a acreditar na função da escola a partir da justificativa histórica de termos confinado as crianças nestes espaços tão somente por acreditarmos serem elas sujeitos sem autonomia - assim como encaramos os indígenas como incapazes, como seres que precisam de tutela?

Não nos voltamos à capacidade das crianças de aprender coisas que não são ditas. Supervalorizamos o ensino oral e a escrita, deixando esquecido o maior meio de comunicação que temos com o mundo que é nosso corpo e nossa capacidade de nos movimentarmos. Na escola que ensinamos, produzimos corpos com a ilusão de que produzimos a mente. E a Educação Física, entendida como disciplina, perpassa as paredes da sala de aula, entrando no refeitório, na cozinha e no pátio, silenciosamente, como se fosse feita apenas de raros momentos na semana, sem pensarmos que dela são feitos todos os momentos da escola. 
Outro fator importante é que em muitos contextos a escola tem se tornado o principal, senão o único, lugar onde as crianças se reúnem, criando uma relação de interação e criação cultural entre pares. De acordo com Francisco (2005), o parque da escola é o espaço de excelência das brincadeiras, embora nele se evidencie "a dicotomia entre a centralidade excessiva nos adultos na sala de referência e a ausência de propostas e de participação nos adultos no parque" (FRANCISCO, 2005, p. I3). Por isso a ideia do parque/pátio como espaço de transgressão, de criação, de cultura por parte das crianças, sendo que este ambiente acaba por se caracterizar em um espaço só delas, sem a intervenção direta dos adultos como acontece em sala de aula. Este paradoxo nos leva a pensar no pátio como o espaço de excelência não apenas das brincadeiras, mas do corpo. Isso também é demonstrado por Francisco, ao afirmar que o espaço construído interno é local de privilégio da mente, e o não construído, o externo, do corpo em movimento. O que na verdade não deveria se constituir numa ruptura mas sim numa continuidade, uma extensão um do outro.

Penso que é aí que se encaixa a importância de pensar o mundo de movimento das crianças sob uma concepção dialógica, como seres que atuam, que refletem, que questionam o seu mundo através do movimento. A partir de uma abordagem fenomenológica, a teoria do movimento humano (KUNZ, 2004) nos mostra a importância de se pensar a percepção, a sensibilidade e a intuição como ações coincidentes, simultâneas ao movimento humano, já que a percepção constitui o nosso ser-no-mundo - "o mundo não é aquilo que penso, mas aquilo que vivo" (KUNZ, 2000, p. 10).

Nesse sentido, o autor destaca os diferentes pontos de vista sobre a definição de movimento, cujos aspectos na área das ciências biológicas e na antropologia se mostram teoricamente distantes entre si. Segundo ele, o movimento humano é estudado nas ciências biológicas apenas por seu viés científico: como um fenômeno físico, quantificável e objetivo. A Biomecânica é responsável por esta compreensão, sendo o movimento humano aí entendido como nada mais do que "o deslocamento do corpo ou de partes deste em um tempo e espaço determinado" (KUNZ, 2004, p. 162). Para o autor, ainda são poucas, infelizmente, as pesquisas que levam em consideração emoções, percepções e sentimentos, que interpretem o movimento humano como uma relação entre estas manifestações humanas e o movimentar-se. O autor sugere que a visão mecanicista do movimento humano poderia ser superada se este fosse interpretado como um fenômeno "antropológico, sócio-cultural e histórico". Dessa maneira, não apenas o ato de se-movimentar deve receber atenção, mas o ser humano que se movimenta e o contexto onde o movimentar-se acontece. Assim, para uma interpretação antropológica do movimento humano, este deve ser interpretado como uma relação de diálogo entre o ser humano e o mundo. 
Daí destaca-se o entendimento do movimentar-se como uma forma fundamental do comportamento humano, na qual se realiza uma compreensão do mundo pelo agir (KUNZ; TREBELS, 2006). Não somos meros espectadores do nosso mundo. Estamos entre as coisas e com elas interagimos. E é daí que somos remetidos a pensar também no quanto as experiências corporais moldam culturas.

Passando por concepções de infância nas sociedades indígenas e ocidental, discutindo a importância do corpo na concepção de pessoa e nas formas de aprendizado, como a Antropologia da Criança, levada ao campo da Educação Física, pode contribuir nesta discussão? $\bigcirc$ que temos a aprender com a abordagem das crianças indígenas em relação ao corpo, ao aprendizado e ao tempo? Talvez desta riqueza de experiências corporais e da liberdade de expressão entre os adultos que surge o maior ensinamento das crianças indígenas à nossa concepção de infância, que permeia toda a nossa prática pedagógica (e de adultos): de que crianças são seres humanos que se movimentam, que tem histórias, experiências e sensações; que se encontram em um determinado contexto situacional e cujos movimentos, que partem de suas percepções, são carregados de sentidos e intencionalidades. É a partir desta reflexão que pretendo adicionar ao debate sobre Educação Física e infância ${ }^{9}$ detalhes importantes na relação de produção e transmissão de conhecimento entre crianças e adultos. Relação esta marcada atualmente por espaços escolares e não escolares, como a escola, a família, as cerimônias, o cotidiano, o corpo e seus adornos. $\bigcirc$ corpo que se expressa ora por gestos, ora por voz, ora pelo silêncio.

Uma grande contribuição da Antropologia no que diz respeito à quebra dos paradigmas que envolvem nossa noção de corpo, parte do conhecimento sobre o conjunto de significados atribuídos pelos sujeitos às suas ações. Assim como Geertz (1978) já nos mostrou que o homem é um animal preso a uma teia de significados que ele mesmo tece, para entender este amplo conjunto de significados temos que observar o que as pessoas estão fazendo. E para isso, devemos deixar de lado toda aquela concepção adultocêntrica de que somente nós, adultos, temos algo a ensinar às crianças.

Assim, esta reflexão pretende ser uma demonstração de que o estilo de vida das sociedades que negamos em nossa formalidade pode compor um ensinamento valioso ao nosso conceito do que é ser criança hoje. Que, independente do contexto

9. Vale ressaltar que no Dicionário Crítico de Educação Física (GONZÁLEZ; FENSTERSEIFER, 2005), obra recente que se propõe a abordar um conjunto de conceitos vinculados pelas produções da área, não se encontram os verbetes "infância" ,"criança" e "brincadeira". Esses conceitos são citados sem maior aprofundamento em outros verbetes como "lúdico", o que sugere lacunas sobre esses estudos na área. 
e da cultura em que se situa, toda criança quer ter voz para falar e ser ouvida, quer ter espaço para se expressar, quer ter o direito de conviver como agente legítima de suas experiências.

\section{What can we learn with indigenous children? Approximations of anthropology of the child to the notions of childhood, culture and body in physical education}

ABSTRACT: This paper proposes to question the notions of childhood, culture and movement in the Physical Education from the contributions of Anthropology of the Child, which demonstrates in the studies in indigenous societies how much identity and child subjectivities are constructed through processes that accomplish through the body. In this discussion, I approach the concepts of childhood in western society, assuming that the child should not be considered as natural or universal category, determined by biological aspects, and that his/her determinations are variables, historically, culturally and socially.

KEYWORDS: Childhood; body; movement; anthropology of the childhood.

\section{¿Qué podemos aprender con los niños indígenas?}

Aproximaciones de la antropología infantil a las nociones de infancia, cultura y movimiento en la educación física

RESUMEN: Este artículo se propone cuestionar las nociones de infancia, cultura y cuerpo en la Educación Física desde las contribuciones de la antropología infantil, que es demostrado en estudios de sociedades indígenas o en cualquier identidad y subjetividad infantil construida por medio de procesos que son realizados a partir de la expresión corporal. En esta reflexión abordo los conceptos de infancia en la sociedad occidental así como el abordaje a la antropología infantil, partiendo del principio que la infancia no debe ser considerada como categoría natural o universal, determinada por aspectos biológicos y que sus determinaciones son variables, históricas, culturales y sociales.

PALABRAS CLAVE: Infancia; cuerpo; movimiento; antropología infantil.

\section{REFERÊNCIAS:}

ARIÈS, P. História Social da Criança e Família. 2. ed. Tradução: Dora Flaksman. Rio de Janeiro: LTC, 1981.

BENJAMIN, W. Reflexões: a criança, o brinquedo, a educação. Tradução: Marcus Mazzari. São Paulo: Summus, 1984. 
BUCKINGHAM, D. Crescer na era das mídias eletrônicas. Tradução: Gilka Girardello; Isabel Orofino. São Paulo: Loyola, 2007.

COHN, C. Antropologia da Criança. Rio de Janeiro: Jorge Zahar, 2005.

COHN, C. Crescendo como um Xikrin: uma análise da infância e do desenvolvimento infantil entre os Kayapó-Xikrin do Bacajá. Revista de Antropologia, São Paulo, v. 43, n. 2, p. 195-222, 2000.

CRUZDE OLIVEIRA, N. Concepção de infância na educação física brasileira: primeiras aproximações. Revista Brasileira de Ciências do Esporte, Campinas, v. 26, n. 3, p. 95- 109, maio 2005.

DAOLIO, J. A educação física escolar como prática cultural: tensões e riscos. Pensar a Prática, Goiânia, v. 8, n. 2, p. 215-226, jul./dez. 2005.

DAOLIO, J. A ruptura natureza/cultura na Educação Física. In: DE MARCO, A. (Org.). Pensando a Educação Motora. Campinas: Papirus, v. OI , p. 59-68, 1995.

FRANCISCO, Z. F. “Zê, tá pertinho de ir pro parque?”. O tempo e o espaço do parque em uma instituição de Educação Infantil. 2005. 199 f. Dissertação (Mestrado em Educação) - Programa de Pós Graduação em Educação, Universidade Federal de Santa Catarina, Florianópolis, 2005.

GEERTZ, C. A interpretação das Culturas. São Paulo: Zahar, 1978.

GIRARDELLO, G. Televisão e imaginação infantil: histórias da Costa da Lagoa. I 998. 349 f. Tese (Doutorado em Ciências da Comunicação), Escola de Comunicação e Artes (ECA), Universidade de São Paulo, São Paulo, 1998.

GONZÁLES, F.; FENSTERSEIFER, P. Dicionário Crítico de Educação Física. ljuí: Unijuí, 2005.

KLINE, S. Out of the Garden: Toys and Children's Culture in the Age of TV Marketing. London/New York: Verso, 1993.

KUNZ, E. Educação Física: Ensino e Mudanças. ljuí: Unijuí, 2004.

KUNZ, E. Esporte: uma abordagem com a fenomenologia. Revista Movimento, Porto Alegre, ano VI, n. I2, p.I-I3, 2000/I.

KUNZ, E. TREBELS, A.H. Educação Física crítico emancipatória: com uma perspectiva da pedagogia alemã do esporte. ljuí: Unijuí, 2006.

MEAD, M. MACGREGOR, F. Growth and Culture, a photographic study of Balinese childhood. New York: GPPS, 1951.

MELATTI, J.; MELATTI, D. A criança Marubo: educação e cuidados. Revista Brasileira de Estudos Pedagógicos, Brasília, v. 62, n. 143, p. 291-301, jan./abr. 1979.

MUNARIM, I. Brincando na escola: o imaginário midiático na cultura de movimento das crianças. 2007. 188 f. Dissertação (Mestrado em Educação) - Programa de Pós Graduação em Educação, Universidade Federal de Santa Catarina, Florianópolis, 2007. 
NUNES, A. O lugar das crianças nos textos sobre sociedades indígenas brasileiras. In: SILVA, A. L.; MACEDO, A. V.; NUNES, A. Crianças indígenas, ensaios antropológicos. São Paulo: Mari/ Fapesp/Global, 2002. p. 236-277.

NUNES, A.; CARVALHO, M. R. Questões metodológicas e epistemológicas suscitadas pela Antropologia da Infância. In: ENCONTRO ANUAL DA ANPOCS, 31 ., 2007, Caxambu, Anais... Caxambu, 2007, p. I-26.

PAIVA, F. S. L. Aprendizagem motora e Educação Física: uma contribuição ao debate. Revista Brasileira de Ciências do Esporte, v. 13, n. 3, p. 345-350, jun. 1992.

SARMENTO, M. J. As Culturas da infância nas encruzilhadas da Segunda Modernidade. In SARMENTO, M. J.; CERISARA, A. B. Crianças e Miúdos: perspectivas sociopedagógicas da infância e educação. Porto: ASA, 2004. p. 9-34.

SEEGER, A.; DA MATTA, R.; VIVEIROS DE CASTRO, E. A construção da pessoa nas sociedades indígenas brasileiras. Boletim do Museu Nacional, Rio de Janeiro, n. 32, p. 2-19, 1979.

SILVA, A. L.; Pequenos xamãs: crianças indígenas, corporalidade e escolarização. In: SILVA, A. L., MACEDO, A. V.; NUNES, A. Crianças indígenas, ensaios antropológicos. São Paulo, Mari/Fapesp/Global, 2002. p. 37-63.

SILVA, A. L.; NUNES, A. Contribuições da etnologia indígena brasileira à antropologia da criança. In: SILVA, A.L.; MACEDO, A. V.; NUNES, A. Crianças indígenas, ensaios antropológicos. São Paulo: Mari/Fapesp/Global, 2002. p. II-33.

TASSINARI, A. Concepções Indígenas de Infância no Brasil. Revista Tellus, Campo Grande, ano 7, n. 13, p. II-25, out. 2007.

PERROTTI, E. A criança e a produção cultural: apontamentos sobre o lugar da criança na cultura. In: ZILBERMANN, R. A produção cultural para a criança, Porto Alegre: Mercado Aberto, 1990, p. 09-27.

WALKERDINE, V. O raciocínio em tempos pós-modernos. Educação e Realidade, Porto Alegre, v. 20, n. 2, p. 207-226, jul./dez. 1995.

Recebido: 03 out. 2009 Aprovado: 20 mar. 201 I

Endereço para correspondência: Iracema Munarim Servidão Ferreira, 110 - Bairro Campeche Florianópolis - SC CEP: 88063-020 